\title{
A Randomized Controlled Trial of Three Years Growth Hormone and Gonadotropin-Releasing Hormone Agonist Treatment in Children with Idiopathic Short Stature and Intrauterine Growth Retardation*
}

\author{
G. A. KAMP, D. MUL, J. J. J. WAELKENS, M. JANSEN, \\ H. A. DELEMARRE-vAN DE WAAL, L. VERHOEVEN-WIND, M. FRÖLICH, \\ W. OOSTDIJK, AND J. M. WIT
}

Department of Pediatrics, Leiden University Medical Center (G.A.K., W.O., J.M.W.), Sophia Children's Hospital Rotterdam, subdivision Endocrinology (D.M.), Catharina Hospital Eindhoven (J.J.J.W.), University Medical Center Utrecht (M.J., L.V.-W.), Free University Hospital Amsterdam

(H.A.D.-v.d.W.), Department of Clinical Chemistry, and Leiden University

Medical Center (M.F.), The Netherlands

\begin{abstract}
We assessed the effectiveness and safety of $3 \mathrm{yr}$ combined $\mathrm{GH}$ and $\mathrm{GnRH}$ agonist ( $\mathrm{GnRHa}$ ) treatment in a randomized controlled study in children with idiopathic short stature (ISS) or intrauterine growth retardation (IUGR). Gonadal suppression, GH reserve, and adrenal development were assessed by hormone measurements in both treated children and controls during the study period.

Thirty-six short children, 24 girls (16 ISS/8 IUGR) and 12 boys ( 8 ISS/4 IUGR), with a height SD score of -2 SD or less in early puberty (girls, B2-3; boys, G2-3), were randomly assigned to treatment (n = 18) with GH (genotropin $4 \mathrm{IU} / \mathrm{m}^{2} \cdot$ day) and GnRHa (triptorelin, 3.75 $\mathrm{mg} / 28$ days) or no treatment $(\mathrm{n}=18)$. At the start of the study mean (SD) age was $11.4(0.56)$ or $12.2(1.12)$ yr whereas bone age was 10.7 $(0.87)$ or $10.9(0.63)$ yrs in girls and boys, respectively.

During 3 yr of study height SD score for chronological age did not change in both treated children and controls, whereas a decreased rate of bone maturation after treatment was observed [mean (SD) 0.55 $(0.21)^{\text {' }} \mathrm{yr}$ '/yr $v s .1 .15(0.37)^{\text {' }} \mathrm{yr} / \mathrm{yr}$ in controls, $P<0.001$, girls and boys together]. Height SD score for bone age and predicted adult height increased significantly after $3 \mathrm{yr}$ of treatment; compared with controls
\end{abstract}

the predicted adult height gain was $8.0 \mathrm{~cm}$ in girls and $10.4 \mathrm{~cm}$ in boys. Furthermore, the ratio between sitting height/height SD score decreased significantly in treated children, whereas body mass index was not influenced by treatment.

Puberty was effectively arrested in the treated children, as was confirmed by physical examination and prepubertal testosterone and estradiol levels. GH-dependent hormones including serum insulinlike growth factor I and II, carboxy terminal propeptide of type I collagen, amino terminal propeptide of type III collagen, alkaline phosphatase, and osteocalcin were not different between treated children and controls during the study period. Thus, a GH dose of $4 \mathrm{IU} / \mathrm{m}^{2}$ seems adequate for stabilization of the $\mathrm{GH}$ reserve and growth in these GnRHa-treated children.

We conclude that 3 yr treatment with GnRHa was effective in suppressing pubertal development and skeletal maturation, whereas the addition of GH preserved growth velocity during treatment. This resulted in a considerable gain in predicted adult height, without demonstrable side effects. Final height results will provide the definite answer on the effectiveness of this combined treatment. (J Clin Endocrinol Metab 86: 2969-2975, 2001)
$S^{n}$ NCE PUBERTY INITIATES the process of epiphysial fusion that determines final height, the first signs of puberty are often perceived as an alarming signal in short children (1), and the question whether therapeutic options exist to improve final height is often asked. If initiated years before the onset of puberty, GH treatment may have beneficial effects on final height in children with idiopathic short stature (ISS) and intrauterine growth retardation (IUGR) (2, $3)$. Once puberty has started, however, GH treatment in these short children has limited value; GH may stimulate a rapid progression through puberty, which is expected to reduce the gain in final height (4-6). The addition of $\mathrm{GnRH}$ agonists

Received September 7, 2000. Revision received February 23, 2001. Accepted February 28, 2001.

Address correspondence and requests for reprints to: Prof. Dr. J. M. Wit, Department of Pediatrics, LUMC J6-204, P.O. Box 9600, 2300 RC Leiden, The Netherlands. E-mail: JMWit@lumc.nl.

* Supported by Pharmacia \& Upjohn AB (Stockholm, Sweden) and Ferring (Hoofddorp, The Netherlands).
(GnRHa) to delay puberty has, therefore, been considered. GnRHa were initially used in children with central precocious puberty (CPP), with beneficial effects on adult height (7-9). Recent trials with GnRHa in short children showed an increment in adult height of $0.5-3.3 \mathrm{~cm}(10,11)$. No controls were included, except for one study with 4 yr treatment with GnRHa vs. placebo, showing a height gain of $7.6 \mathrm{~cm}$ compared with initial prediction in the GnRHa treated children and of $10.3 \mathrm{~cm}$ compared with placebo group. The study population, however, was very heterogeneous, and, therefore, the results are difficult to interpret (12). More recent studies, using the combined treatment of GH and GnRHa in children with ISS or IUGR, report a gain in final height prediction between -0.5 to $10 \mathrm{~cm}(1,13-17)$, but none of these studies used randomized controls.

To answer the question whether GH and GnRHa treatment may improve final height in pubertal children with ISS and IUGR we designed a randomized controlled study with 3 yr treatment with combined GH and GnRHa treatment in 
24 girls and 12 boys with ISS or IUGR. We verified the effectiveness of gonadal suppression by physical examinations and by measurements of sex steroids in all children. To assess the GH reserve during treatment, we yearly measured insulin-like growth factor (IGF)-I, IGF-II, IGF-binding protein (BP)-3, and markers of collagen and bone metabolism, all GH-dependent hormones (Kamp, G. A., A. H. Zwinderman, J. van Doorn, W. Hackeng, M. Frolich, E. Schönau, and J. M. Wit, submitted for publication). Adrenal hormones were measured to search for a possible effect of treatment on adrenal development. Here, we present data obtained during the first $3 \mathrm{yr}$ of the study.

\section{Patients and Methods}

Forty children were randomized for either combined treatment with GH and GnRHa or no treatment. GH (Genotropin, Pharmacia and Upjohn $\mathrm{AB}$, Stockholm, Sweden) was given in a dose of $4 \mathrm{IU} / \mathrm{m}^{2} \cdot$ day sc, which is equivalent to $0.14 \mathrm{IU}(0.05 \mathrm{mg}) / \mathrm{kg}$ body weight $\cdot$ day. GnRHa [triptorelin (Decapeptyl, Ferring, Hoofddorp, The Netherlands); because Decapeptyl was withdrawn by Ferring in 1998, we used the same preparation from Ipsen] was given in a dose of $3.75 \mathrm{mg}$ im every 28 days. The randomization was performed separately in children with a known history of IUGR, defined as a birth length $\leq-2$ SD score (18). Directly after randomization, two patients randomized for treatment refused treatment and two controls refused follow-up. Additionally, one ISS boy and one IUGR girl, both controls, became drop-outs. We report 3-yr data of 18 treated (12 ISS and 6 IUGR/ 6 boys and 12 girls) and 16 controls (11 ISS and 5 IUGR/ 5 boys and 11 girls).

The protocol was reviewed and approved by the medical ethics committees at the four participating centers [Catharina Hospital Eindhoven $(n=12)$, Wilhelmina Childrens Hospital Utrecht $(n=12)$, Free University Hospital Amsterdam $(\mathrm{n}=10)$, and Sophia's Childrens Hospital Rotterdam $(n=2)]$, and the parents of all children gave written consent for the study. When appropriate, the consent of the children was also obtained.

Inclusion criteria were G2 or G3 in boys (testicular volume of $\geq 4$ and $\leq 10 \mathrm{~mL}$ ) and B2 or B3 in girls, an actual height $\leq-2.0$ sD score (19) or between -1.0 and -2.0 sD score with a predicted adult height $\leq-2.0$ sD score [according to Bayley and Pinneau (20)], and a chronological age and bone age less than 12 and $13 \mathrm{yr}$ in girls and boys, respectively. Furthermore, a maximum serum GH level $>10 \mathrm{ug} / \mathrm{L}(1 \mathrm{ug}=2 \mathrm{IU}$, The First International Reference Preparation of hGH, MRC London, code $66 / 217$ was used as standard) after provocation (exercise, arginine, clonidine, L-dopa, or glucagon) and a normal ratio of sitting height/ subischial leg length (between P3 and P97) (21) were established. At the time of inclusion, blood screening tests and urinanalysis were normal, and none had evidence of malnutrition or hormonal or systemic disease.

All children were evaluated at baseline. Then, the children of the treatment group were followed every 3 months during treatment and at least once a year thereafter. Children in the control group were followed on a yearly basis. Evaluations included measurements of height [mean of four measurements was performed by the same observer (L.V.) at the same hour of day on a Harpenden stadiometer], sitting height [mean of two measurements (L.V.)], and weight. Pubertal staging was assessed by one investigator (G.A.K.) in all children at all visits, according to the method of Tanner. The Prader orchidometer was used to determine testicular size in boys.

Height was expressed as SD score for chronological age (CA) and for bone age (BA) according to Dutch references (19). Body mass index (BMI) was calculated [weight/ $\left(\right.$ height $\left.^{2}\right)$ ] and expressed as SD score (22). Sitting height and sitting height/height were also expressed as SD score (21). Target height was calculated (father's height + mother's height + or $-12 \mathrm{~cm}$ for boys and girls, respectively) $/ 2+3 \mathrm{~cm}$ (for the secular trend) and expressed as SD score (19). BA radiographs were measured yearly in all children and were determined according to the method of Greulich and Pyle (23) by one independent investigator. To evaluate the effect of treatment, we used the gain in predicted adult height (PAH), defined as the difference between the height prediction at start and after $3 \mathrm{yr}$ of treatment or follow-up. In girls, a yearly ultrasound of uterus and ovaries was performed. We measured the volumes and examined the occurrence of ovarian cysts.

\section{Hormone analysis}

Laboratory tests at baseline and at yearly visits included full blood count, serum free $\mathrm{T}_{4}, \mathrm{TSH}, \mathrm{LH}, \mathrm{FSH}$, estradiol in girls and testosterone in boys, blood $\mathrm{HbAlc}$, fasting blood glucose, serum fasting insulin, IGF-I IGF-II, IGFBP-3, leptin, DHEA, DHEAS, androstenedione, carboxy terminal propeptide of type I collagen (PICP), amino terminal propeptide of type III collagen (PIIINP), alkaline phosphatase, and osteocalcin. Plasma levels of IGF-I, IGF-II, and IGFBP-3 were determined in one assay in the endocrine laboratory of the Wilhelmina Children's Hospital, Utrecht, on samples that had been stored at $-20 \mathrm{C}$ for a maximum of $4 \mathrm{yr}$. These assays have been described previously (24). The levels of IGF-I, IGF-II, and IGFBP-3 were expressed as $\mathrm{ng} / \mathrm{mL}$ and compared with references based on measurements in 906 healthy individuals. Smoothed references for three plasma parameters and three ratios were constructed using the LMS method (25). This method allows to find the best transformation of data that lack a normal distribution (as do all these parameters), yielding a smoothed and statistically valid function. Serum leptin $(\mathrm{ng} / \mathrm{mL}$ ) was measured by RIA (Linco Research Inc., St. Charles, MO). PICP [normal range, $200-1000 \mathrm{ug} / \mathrm{L}$ (mean $\pm 2 \mathrm{sD}$ ), decreases with age from 2-16 yr] and PIIINP [normal range, 5-18 ug/L (mean $\pm 2 \mathrm{sD}$ ), decreases with age from 2-16 yr] were measured with RIA kits (Orion Diagnostics, Helsinki, Finland). Serum alkaline phosphatase (IU/L) was measured with the VITROS analyzer and osteocalcin [normal range, 1.8-6.6 ug/L (mean $\pm 2 \mathrm{sD}$ )] with a RIA kit (DiaSorin, Inc., Stillwater). Serum LH (IU/L) and FSH (IU/L) were performed with a solid phase, time resolved immunofluorometric assay (Wallac, Inc., Turku, Finland). Serum testosterone (nmol/L, in boys), DHEA ( $\mathrm{nmol} / \mathrm{L})$, and androstenedione $(\mathrm{nmol} / \mathrm{L}$ ) were measured with solid phase RIAs (Diagnostic Products, Los Angeles, CA). Serum estradiol (pmol/L, in girls) was also measured with a sensitive solid phase RIA (Orion, ESPO, Finland) and DHEAS with an in-house developed RIA [Leiden, Department of Clinical Chemistry (M.F.)]. All samples were measured in one assay on samples that had been stored at $-20 \mathrm{C}$ for a maximum of $4 \mathrm{yr}$.

\section{Statistics}

Results are expressed as mean \pm SEM or SD. The statistical analysis comprised a paired $t$ test for comparisons between data at baseline and after $3 \mathrm{yr}$, and when appropriate for non-normal distribution we used the Wilcoxon signed rank test. Differences between the treated children and controls were tested by Student's $t$ test or Mann-Whitney tests. Correlation analysis was performed appropriate for the distribution of the variable. Changes in variables during the study period between treated patients and controls were analyzed by repeated measurement analysis. Reported are the changes in time between groups and changes in time for both groups together.

\section{Results}

\section{Auxology}

Table 1 shows the auxological data at baseline and after 3 yr of study for ISS girls, ISS boys, IUGR girls, and IUGR boys separately. There was no significantly different pattern between these four subgroups in changes in BA, height velocity (HV), height SD score for CA, height SD score for BA, BMI SD score, or in $\mathrm{PAH}$ in $\mathrm{cm}$ or SD score. Combined auxological data of treated and control children are shown in Figs. 1-3 and in Table 2.

BA advanced significantly less in $\mathrm{GH}+\mathrm{GnRHa}$-treated children compared with controls [0.55 (0.05) ' $\mathrm{yr}^{\prime} / \mathrm{yr}$ vs. 1.15 (0.09) ' $\mathrm{yr}^{\prime} / \mathrm{yr}, P<0.001$, all girls and boys together]. In subgroups, a significant difference in BA was seen in treated compared with control ISS boys after 3 yr of study (Table 1). $\mathrm{HV}$ decreased significantly $(P<0.001)$ in the GH+GnRHatreated children from $7.0(0.32) \mathrm{cm} / \mathrm{yr}$ during the first year 


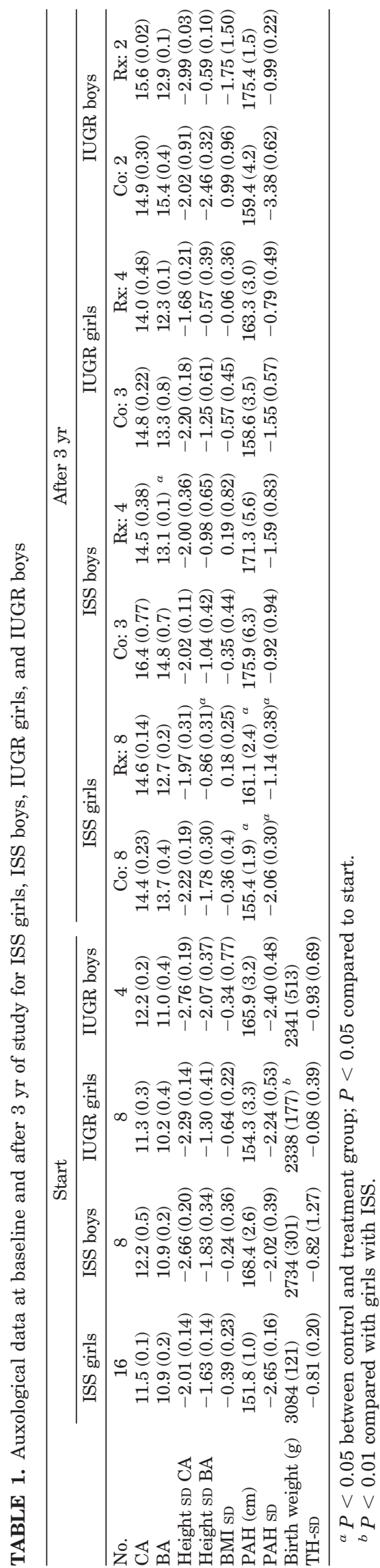

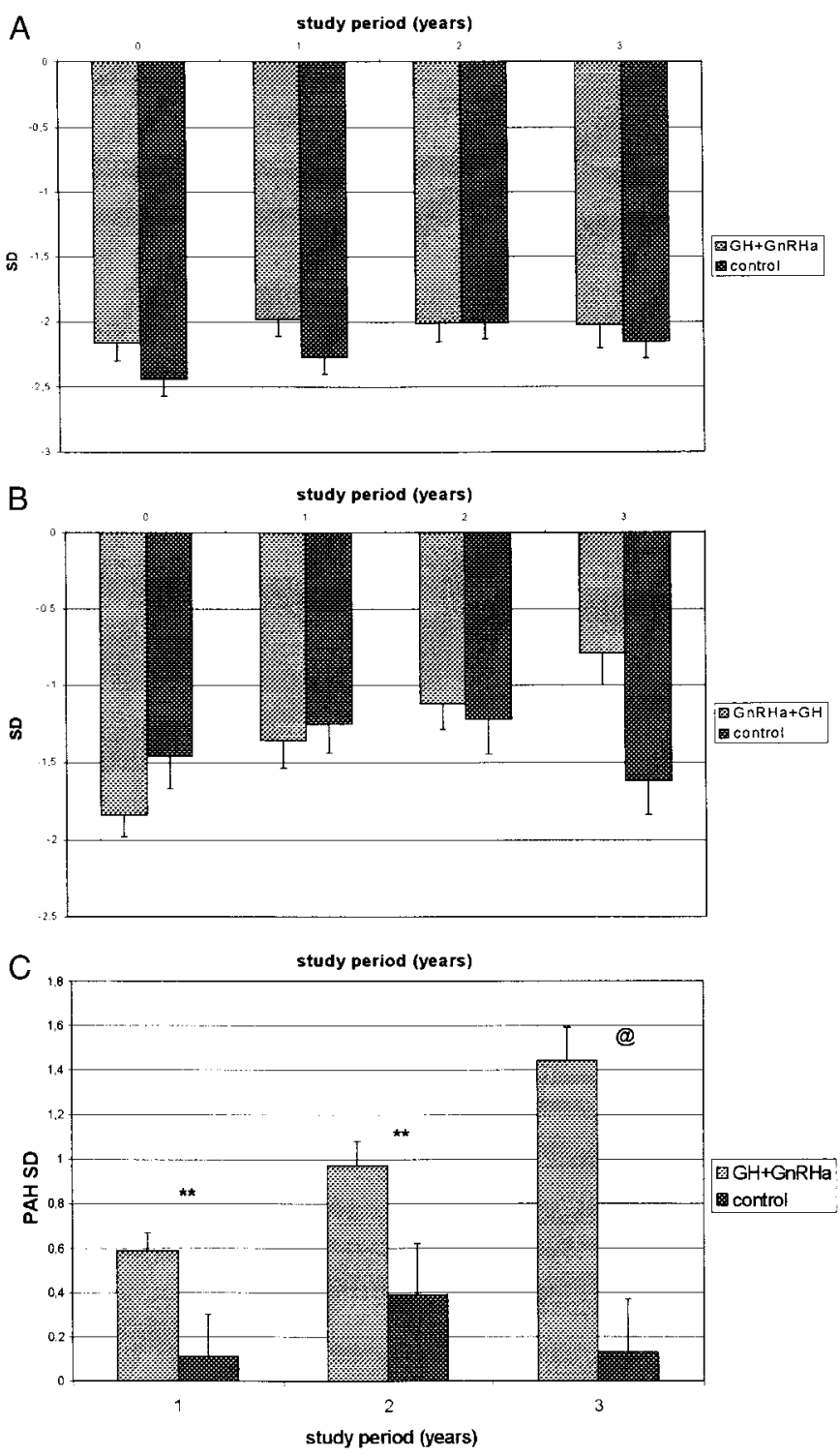

FIG. 1. Height SD score for CA (A) and for BA (B) during the study period. Height SD for CA does not change in time; height SD for BA data show significant differences in time and between groups $(P<$ 0.001). C, Increase in PAH SD compared to the initial height prediction. **, $P<0.05$; @, $P<0.001$.

of treatment to $5.4(0.24)$ and $4.9(0.30) \mathrm{cm} / \mathrm{yr}$ during the second and third year, respectively. In the control group HV was $7.4(0.51), 7.0(0.53)$ and $4.7(0.4) \mathrm{cm} / \mathrm{yr}$ during the first, second, and third year of study, respectively (third year HV compared with the first year HV: $P<0.05)$. Height SD score for $\mathrm{CA}$ did not change during $3 \mathrm{yr}$ of study in all groups (see Fig. 1A for GH+GnRHa vs. controls and Table 1 for subgroups). Height SD score for BA improved significantly in $\mathrm{GH}+\mathrm{GnRHa}$-treated children compared with a decrease in controls $(P<0.001, \mathrm{n}=30$, Fig. 1B). In subgroups, in ISStreated girls height SD score for BA was significantly different between start of study and after 3 yr (Table 1).

The changes in PAH in $\mathrm{cm}$ or SD score were significantly higher in $\mathrm{GH}+\mathrm{GnRHa}$-treated children compared with controls $(P<0.001)$; the change in PAH sD score is shown in Fig. 
A

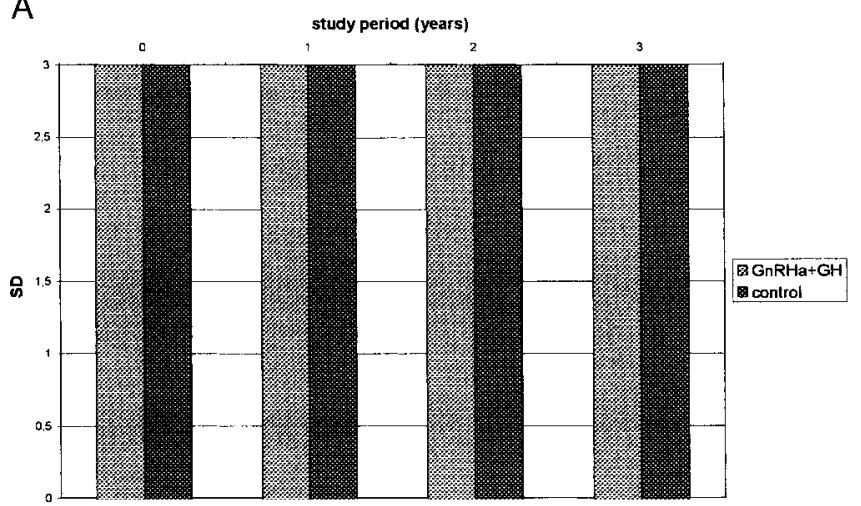

B

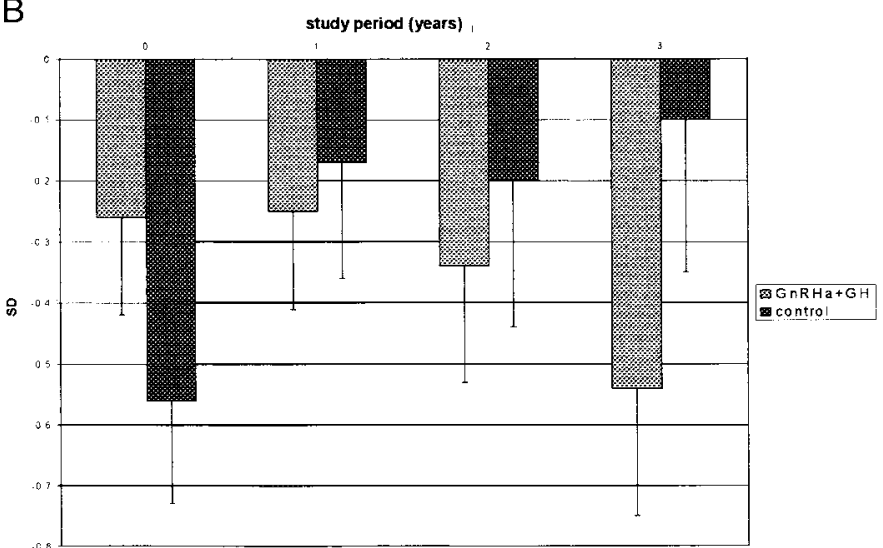

FIG. 2. Proportional growth during the study period, expressed as SD score. A, Sitting Height SD: significant difference in time and between groups $(P<0.01)$. B, Sitting Height/Height SD: significant difference between groups $(P<0.05)$

1C. The absolute values for changes in $\mathrm{PAH}(\mathrm{cm})$ between the start of study and after $3 \mathrm{yr}$ are summarized in Table 2. There was no significant difference between ISS and IUGR children or between boys and girls in change in $\mathrm{PAH}$. In treated children, age, BA, height SD score for CA, height SD score for BA, BMI SD score, or pubertal stage at start of treatment, IGF-I, IGF-II, IGFBP-3 at start of treatment, birth weight, or target height SD score did not significantly correlate with the change in PAH after 3 yr of treatment (univariate nonparametric correlations).

BMI sD score did not change during the study period, in both groups. There was a significant change in sitting height SD score $(P=0.05)$ and in the ratio sitting height to height SD score $\left(\mathrm{SH}_{\mathrm{Ht}}, P=0.016\right)$ in treated children compared with controls. After $3 \mathrm{yr}$ of study, $\mathrm{SH}_{\mathrm{Ht}}$ changed -0.33 (0.77) SD score in the treated group (having relatively longer legs after $3 \mathrm{yr}$ of treatment) compared with $+0.43(0.83)$ sD score in controls (Fig. 2).

\section{Puberty}

At the start of the study period no significant differences were present between treated children and controls with regard to Tanner stage. Pubertal development was effectively arrested in the children treated with GH and GnRHa, whereas puberty progressed in the control group. Figure 3
A

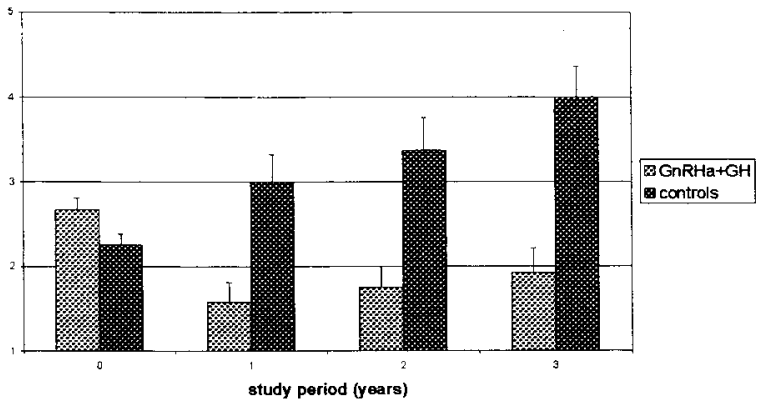

B

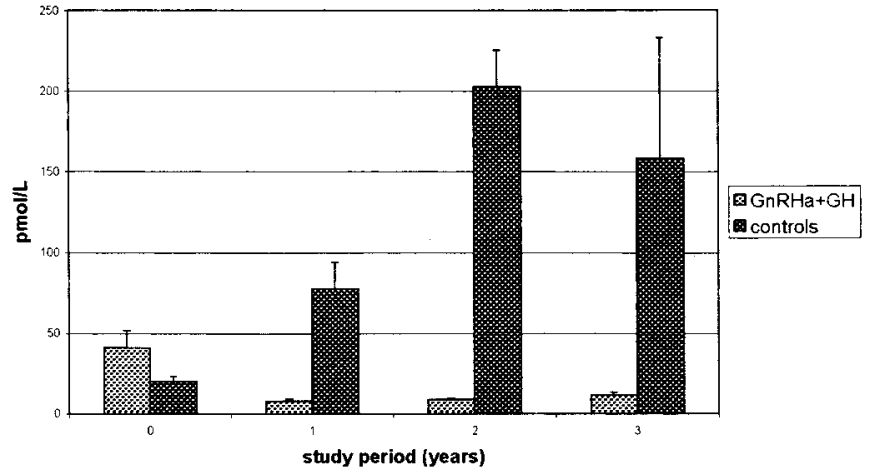

C

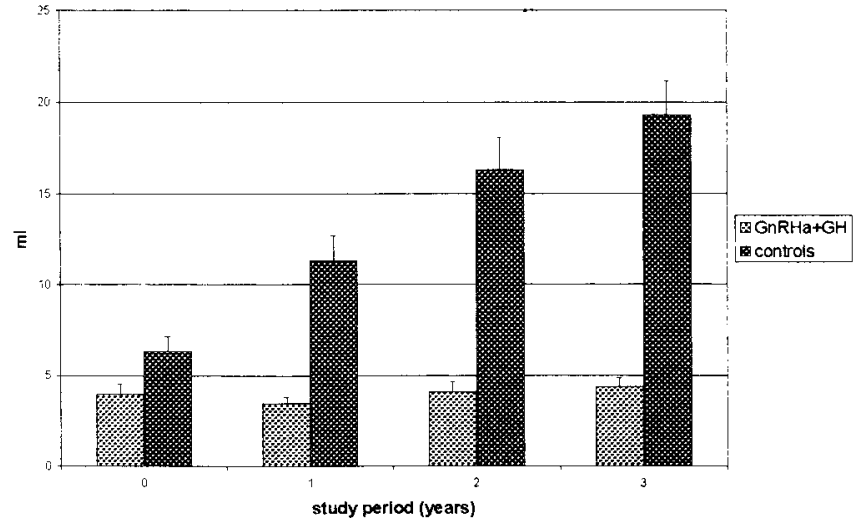

$\mathrm{D}$

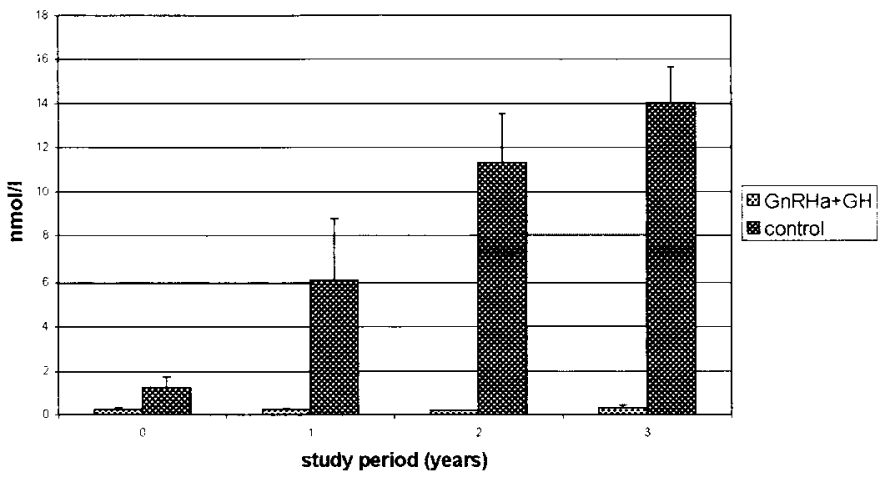

FIG. 3. Suppression of puberty during the study period. A, Tanner breast stage in girls. B, Serum estradiol levels in girls. C, Mean testicular volume in boys. D, Serum testosterone levels in boys. Statistical differences are not shown in this panel. 
TABLE 2. Changes (mean \pm SEM) in PAH in $\mathrm{cm}$ between the start and after 3 yr of study

\begin{tabular}{lrrr}
\hline & No. & \multicolumn{1}{c}{ Control } & GH + GnRHa \\
\hline Girls & 23 & $2.4(1.69)$ & $10.4(1.24)$ \\
Boys & 11 & $-3.9(2.09)$ & $6.5(0.87)$ \\
IUGR girls & 7 & $0.3(5.87)$ & $11.1(1.72)$ \\
ISS girls & 16 & $3.1(1.27)$ & $10.1(1.68)$ \\
IUGR boys & 4 & $-3.6(2.40)$ & $6.5(0.30)$ \\
ISS boys & 7 & $-4.1(4.50)$ & $6.6(1.58)$ \\
\hline
\end{tabular}

shows the Tanner breast stage in relation to estradiol levels in girls and the mean testicular volume in relation to testosterone levels in boys. Ultrasound evaluation of uterus volume and ovarian volumes in girls showed reduction in ovarian volumes in the treated girls. We did not observe any abnormalities in the ovaries (indicative for the development of polycystic ovaries) or uterus by ultrasound in the children on combined treatment.

\section{Hormonal data}

Serum free $\mathrm{T}_{4}, \mathrm{TSH}$, blood $\mathrm{HbAlc}$, fasting blood glucose, and serum fasting insulin remained within the normal range in all children during the study period. Figure 4 shows the serum IGF-I, IGF-II, and IGFBP-3 levels (ng/mL) for treated children and controls. Serum IGF-I and IGFBP-3 levels were approximately 0 SD score, whereas serum IGF-II levels were around -1 SD score. Serum IGF-I (ng/mL or SD score, or IGF-II (ng/mL or SD score) were not different at start of study or during $3 \mathrm{yr}$ of follow-up between treated children and controls, whereas IGFBP-3 (ng/mL or SD score) levels in controls decreased significantly in comparison with treated children during 3 yr of follow-up ( $P=0.01)$. With the exception of androstenedione, serum leptin, DHEA, DHEAS, PICP, PIIINP, osteoalcin, and alkaline phosphatase levels were also not different between treated and control children during $3 \mathrm{yr}$ of follow-up. All hormone levels increased significantly with age in both treated and control children (Table 3).

Serum leptin levels did not significantly differ between controls and treated children. Pearson correlations between BMI SD score and serum leptin levels showed no consistent pattern: significant correlations were found at start and at 2 yr in girls $(P<0.05)$ and at 1 and at 3 yr in boys $(P<0.01)$. Obesity defined as BMI SD score more than 2 was only present in 1 boy in the GH+GnRHa group at one time point.

\section{Discussion}

Combined treatment with GH and GnRHa in short children with ISS or IUGR in a randomized controlled trial resulted in an unchanged height SD score for CA and a decreased rate of bone maturation. Thus, height SD score for $\mathrm{BA}$ and PAH increased significantly after $3 \mathrm{yr}$ of treatment. Compared with controls the predicted height gain was $8.0 \mathrm{~cm}$ in girls and $10.4 \mathrm{~cm}$ in boys. Furthermore, body proportions changed in favor of relatively longer legs in treated children, and BMI was not influenced by treatment. This study is the first randomized controlled trial in a relative large group of children with ISS or IUGR. A placebo-controlled study with 3-month follow-up visits for both treated children and con-

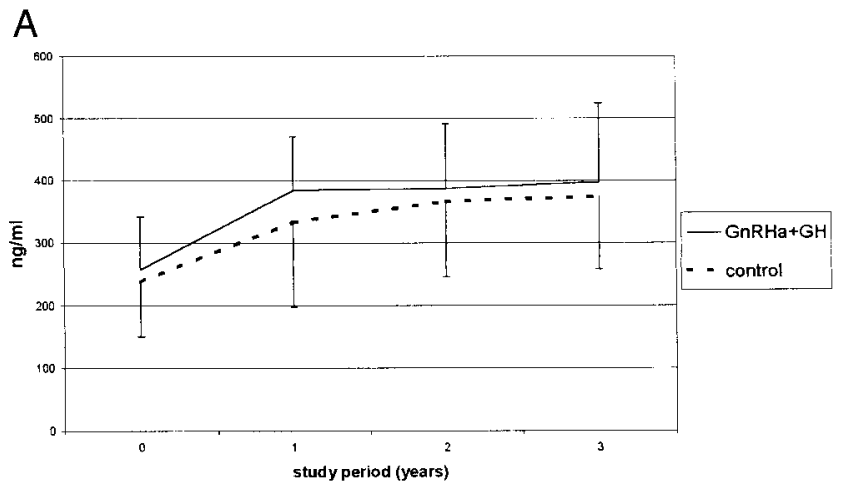

B

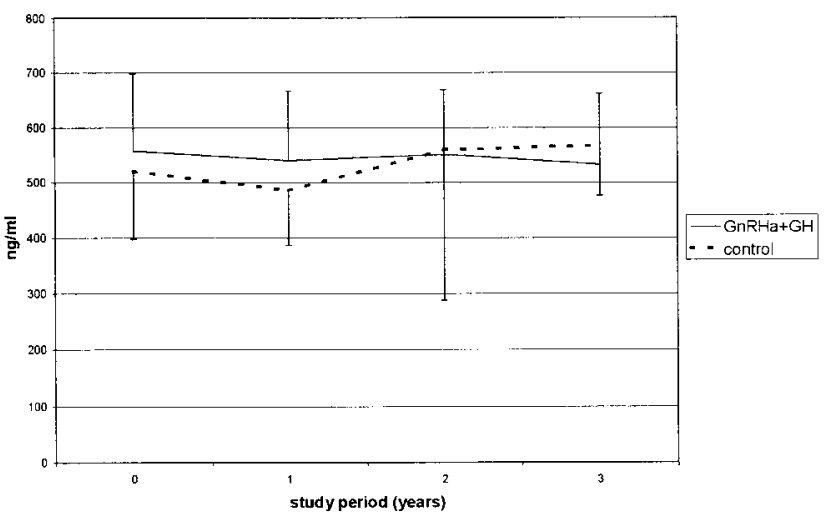

C

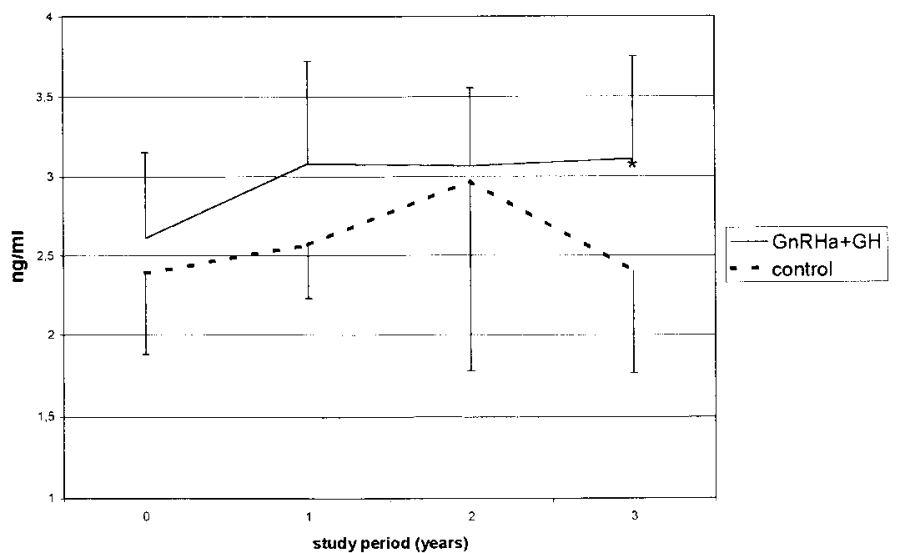

FIG. 4. IGF-I, IGF-II, and IGFBP3 levels during the study period (mean $\pm \mathrm{SD})$. A, IGF-I levels $(\mathrm{ng} / \mathrm{mL})$ increase significantly in both groups during in time $(P<0.001)$. B, IGF-II levels $(\mathrm{ng} / \mathrm{mL})$. C, IGFBP3 levels $(\mathrm{ng} / \mathrm{mL})$, showing a significant difference in time $(P<0.001)$ and between groups $(P=0.01)$.

trols would have been ideal to exclude all factors that could have altered the results. However, for ethical reasons and to keep the controls in the study, we chose yearly follow-ups and no placebo injections in controls.

Previous studies using the combined treatment of GH and GnRHa show considerable variability in gain of $\mathrm{PAH}$, ranging from -0.7 to $10.5 \mathrm{~cm}(1,13,14,16,17,26)$. Results of two of these studies seem comparable with our study $(16,26)$ : the gain in PAH of $9.3 \mathrm{~cm}$ in a group of seven girls reported by Saggese et al. (27) was reduced to $6.3 \mathrm{~cm}$ after comparison 
TABLE 3. Hormonal data (mean \pm SEM) at the start of study and after $3 \mathrm{yr}$ for control and GH+GnRHa-treated children

\begin{tabular}{|c|c|c|c|c|c|c|}
\hline & \multicolumn{2}{|c|}{ Start } & \multicolumn{2}{|c|}{ After $3 \mathrm{yr}$} & \multirow{2}{*}{$\begin{array}{c}\text { Difference in time, } \\
\text { between groups }\end{array}$} & \multirow{2}{*}{$\begin{array}{l}\text { Difference in time, } \\
\text { whole group }\end{array}$} \\
\hline & Control & $\mathrm{Rx}$ & Control & $\mathrm{Rx}$ & & \\
\hline Leptin (ng/mL) & $3.8 \pm 0.5$ & $4.2 \pm 2.5$ & $6.1 \pm 1.1$ & $7.7 \pm 1.1$ & NS & $P<0.001$ \\
\hline DHEA (nmol/L) & $4.9 \pm 0.7$ & $7.3 \pm 1.2$ & $10.3 \pm 3.7$ & $13.1 \pm 5.9$ & NS & $P<0.001$ \\
\hline DHEAS (nmol/L) & $1.7 \pm 0.3$ & $1.7 \pm 0.3$ & $2.7 \pm 1.3$ & $3.2 \pm 0.3$ & NS & $P<0.001$ \\
\hline Androstenedione $(\mathrm{nmol} / \mathrm{L})$ & $1.5 \pm 0.1$ & $2.2 \pm 0.4$ & $2.9 \pm 0.7$ & $2.8 \pm 0.3$ & $P=0.01$ & $P<0.001$ \\
\hline PICP (ug/L) & $275.4 \pm 22.0$ & $321.5 \pm 30.6$ & $251.3 \pm 40.5$ & $272.2 \pm 14.7$ & $\mathrm{NS}$ & $P<0.01$ \\
\hline PIIINP (ug/L) & $8.8 \pm 0.8$ & $9.0 \pm 0.7$ & $8.1 \pm 0.8$ & $10.0 \pm 0.8$ & NS & $P=0.01$ \\
\hline Osteocalcin (ug/L) & $5.8 \pm 0.7$ & $5.8 \pm 0.6$ & $7.9 \pm 1.2$ & $8.1 \pm 0.7$ & NS & $P<0.01$ \\
\hline Alkaline phosphatase (IU/L) & $250.3 \pm 17.0$ & $210.2 \pm 10.4$ & $179.5 \pm 23.6$ & $183.4 \pm 21.9$ & NS & $P<0.01$ \\
\hline
\end{tabular}

with a historical control group. The same pattern was observed in our study in 23 girls, with a reduction of 10.4 to 8.0 $\mathrm{cm}$ when compared with randomized controls. Pasquino et al. (16) also reported a gain of $10.5 \mathrm{~cm}$ in girls, but no controls were included. A recent randomized controlled study of the effect of the addition of GnRHa to GH treatment in seven GH-deficient individuals showed a gain in near final height of $1.4 \mathrm{sD}$ score or $9 \mathrm{~cm}$ (27). After comparison with randomized controls the gain in PAH in our 11 boys increased from 6.5 to $10.4 \mathrm{~cm}$. The decrease in height prediction in nontreated short boys shows that this prediction method is overestimating final height in boys. This finding is in line with the overestimation of final height in untreated ISS boys, as we suggested earlier (28). Contrasting our expectations based on findings from previous reports, a relative young BA or an early pubertal stage were not predictive for a relative large gain in adult height. This finding may have clinical applications for future treatment of older children in whom puberty has progressed substantially. Thus, after 3 yr of study our results are encouraging. However, the suggested gain in final height is entirely based on the extent to which BA advancement was delayed in the treated children and only final height data will provide the definite answer on the effectiveness if this combined treatment. The final height gain may be probably less than 8 to $10 \mathrm{~cm}$, as we have learned from experience in previous studies in CPP (7).

The sitting height SD score and the ratio of sitting height to height SD score decreased significantly in both treated girls and treated boys during the study period. This indicates that delaying puberty in our study has resulted in relatively longer legs. This result is in accordance with the observation in hypogonadotropic hypogonadism, who provide a natural experiment of pubertal delay. These men also have relatively longer legs compared with their trunk at final height (29). At final height some change in body proportions may also be present in treated children, but we expect that the trunk to leg ratio will remain within the normal range. Our data on body proportions are in contrast with the findings at near final height in a recent study on GH-deficient children where the addition of GnRHa resulted in no change in body proportions (27).

The clinical observation that treatment with GnRHa may lead to obesity could not be confirmed by changes in BMI SD score or leptin levels in our study, even when data of boys and girls were analyzed separately (30). Moreover, we could not identify a consistent pattern between changes in BMI SD score and changes in leptin. It has to be emphasized that a BMI SD score change is not a good marker of change in fat mass, particularly during puberty. Another explanation for the absence of obesity in our treated children may be the result of the combined treatment of GnRHa and GH we used. The probable effect of GnRHa on induction of fat mass that is usually reflected by increased leptin levels (31) may have been counterbalanced by the anabolic effect of GH on muscle mass in our treated children.

The therapeutic efficacy in terms of suppressing puberty and the good compliance to treatment were shown by the absence of progression of puberty at clinical assessments. This was further confirmed at the biochemical level by prepubertal levels of serum estradiol in girls and serum testosterone in boys during treatment. The development of polycystic ovaries, a previously suggested side effect of GnRHa treatment (P. Hindmarsh, personal communication), was not observed in the ultrasound studies in our treated children.

The decreased growth rate after GnRHa treatment without $\mathrm{GH}$, as was observed in previous studies, may be explained by a reduction of pituitary GH secretion after withdrawal of sex steroids (32). The unchanged height SD score for CA after treatment in our study suggests that the addition of $\mathrm{GH}$ treatment seems to counteract this mechanism. Therefore, the combined treatment resulted in preservation of growth during treatment while a delay in bone maturation was accomplished. Assessments of IGF-I, IGF-II, IGFBP-3, PICP, PIIINP, alkaline phosphatase, and osteocalcin suggest that a $\mathrm{GH}$ dose of $4 \mathrm{IU} / \mathrm{m}^{2}$.day is needed for replacing the $\mathrm{GH}$ secretion in puberty in these GnRHa-treated children. The assumption that adrenal development is not altered by GnRHa treatment was confirmed by the measurements of DHEA and DHEAS. All androgens increased with age in both groups. Androstenedione levels, however, increased significantly less after 3 yr of study in treated children compared with controls.

We conclude that 3 yr treatment with GnRHa was effective in suppressing pubertal development, whereas the addition of GH preserved the growth potential during treatment. This resulted in a considerable gain in predicted adult height, without demonstrable side effects. Final height results will provide the definite answer on the effectiveness of this treatment regimen.

\section{Acknowledgment}

We thank Trudy Hofland and Erik Herdes for help with the clinical patient care. We also thank Koos Zwinderman for statistical assistance and Germa van Tooten, Wil Hackeng, and Jaap van Doorn for help with the hormone assays. We are grateful to Pharmacia-Upjohn (Woerden, The Netherlands) for continuing supply of recombinant hGH. 


\section{References}

1. Balducci R, Toscano V, Mangiantini A, et al. 1995 Adult height in short normal adolescent girls treated with gonadotropin-releasing hormone analog and growth hormone. J Clin Endocrinol Metab. 80:3596-3600.

2. Hintz RL, Attie KM, Baptista J, Roche A. 1999 Effect of growth hormone treatment on adult height of children with idiopathic short stature. Genentech Collaborative Group. N Engl J Med. 340:502-507.

3. Sas T, de Waal W, Mulder P, et al. 1999 Growth hormone treatment in children with short stature born small for gestational age: 5-year results of a randomized, double-blind, dose-response trial. J Clin Endocrinol Metab. 84:3064-3070.

4. Hindmarsh PC, Brook CG. 1996 Final height of short normal children treated with growth hormone. Lancet. 348:13-16.

5. Stanhope R, Albanese A, Hindmarsh P, Brook CG. 1992 The effects of growth hormone therapy on spontaneous sexual development. Horm Res. 38(Suppl 1):9-13.

6. Rekers-Mombarg LTM, Kamp GA, Massa GG, Wit JM, Group DGHW. 1999 Influence of growth hormone treatment on pubertal timing and pubertal growth in children with idiopathic short stature. J Pediatr Endocrinol Metab. 12:611-622.

7. Oostdijk W, Rikken B, Schreuder S, et al. 1996 Final height in central precocious puberty after long-term treatment with a slow-release GnRH agonist. Arch Dis Child. 75:292-297.

8. Pasquino AM, Pucarelli I, Segni M, Matrunola M, Cerrone F. 1999 Adult height in girls with central precocious puberty treated with gonadotropinreleasing hormone analogs and growth hormone. J Clin Endocrinol Metab. 84:449-452.

9. Carel JC, Roger M, Ispas S, et al. 1978 Final height after long-term treatment with Triptorelin slow release for central precocious puberty: importance of statural growth after interruption of treatment. J Clin Endocrinol Metab. 84:1973-1978.

10. Lindner D, Job JC, Chaussain JL. 1993 Failure to improve height prediction in short stature pubertal adolescent by inhibiting puberty with luteinizing hormone-releasing hormone analogue. J Pediatr. 152:393-396.

11. Carel JC, Hay F, Coutant R, Rodrigue D, Chaussain JL. 1996 Gonadotropinreleasing hormone agonist treatment of girls with constitutional short stature and normal pubertal development. J Clin Endocrinol Metab. 81:3318-3322.

12. Municchi G, Rose SR, Pescovitz OH, Barnes KM, Cassorla FG, Cutler Jr GB. 1993 Effects of Deslorelin-induced pubertal delay on the growth of adolescents with short stature and normally timed puberty: preliminary results. J Clin Endocrinol Metab. 77:1334-1339.

13. Job JC, Toublanc JE, Landier F. 1994 Growth of short normal children in puberty treated for 3 years with growth hormone alone or in association with gonadotropin-releasing hormone agonist. Horm Res. 41:177-184.

14. Lanes R, Gunczler P. 1998 Final height after combined growth hormone and gonadotrophin-releasing hormone analogue therapy in short healthy children entering into normally timed puberty. Clin Endocrinol. 49:197-202.

15. Tanaka T, Satoh M, Yasunaga T, Horikawa R, Tanae A, Hibi I. 1997 GH and $\mathrm{GnRH}$ analog treatment in children who enter puberty at short stature. J Clin Endocrinol Metab. 10:623-628.

16. Pasquino AM, Pucarelli I, Roggini M, Segni M. 2000 Adult height in short normal girls treated with gonadotropin-releasing hormone analogs and growth hormone. J Clin Endocrinol Metab. 85:619-622.

17. Saggese G, Cesaretti G, Barsanti S, Rossi A. 1995 Combination treatment with growth hormone and gonadotropin-releasing hormone analogs in short normal girls. J Pediatr. 126:468-473.

18. Usher R, McLean F. 1969 Intrauterine growth of live-born Caucasian infants at sea level: standards obtained from measurements in 7 dimensions of infants born between 25 and 44 weeks of gestation. J Pediatr. 74:901-910.

19. Roede MJ, Wieringen IC van. 1985 Growth diagrams 1980. Netherlands third nation-wide survey. Tijdschr Soc Gezondheidszorg. 63(Suppl 1):11-32.

20. Bayley N, Pinneau SR. 1952 Tables for predicting adult height for skeletal age: revised for use with the Greulich-Pyle hand standards. J Pediatr. 40:423-441.

21. Gerver WJM, Bruin R de. 1996 Paediatric morphometrics; a reference manual. Utrecht: Bunge.

22. Cole TJ, Roede MJ. 1999 Centiles of body mass index for Dutch children aged 0-20 years in 1980 - a baseline to assess recent trends in obesity. Ann Hum Biol. 26:303-308.

23. Greulich WW, Pyle SI. 1959 Radiographic atlas of skeletal development of the hand and wrist, ed 2. Stanford, CA: Stanford University Press.

24. Rikken B, van Doorn J, Ringeling A, Van den Brande JL, Massa G, Wit JM. 1998 Plasma levels of insulin-like growth factor (IGF)-I, IGF-II and IGF-binding protein-3 in the evaluation of childhood growth hormone deficiency. Horm Res. 50:166-176.

25. Cole TJ. 1989 Using the LMS method to measure skewness in the NCHS and Dutch national height standards. Ann Hum Biol. 16:407-419.

26. Saggese G, Pasquino AM, Bertelloni S, et al. 1995 Effect of combined treatment with gonadotropin releasing hormone analogue and growth hormone in patients with central precocious puberty who had subnormal growth velocity and impaired height prognosis. Acta Paediatr. 84:299-304.

27. Mericq MV, Eggers M, Avila A, Cutler Jr GB, Cassorla F. 2000 Near final height in pubertal growth hormone $(\mathrm{GH})$-deficient patients treated with $\mathrm{GH}$ alone or in combination with luteinizing hormone-releasing hormone analog: results of a prospective, randomized trial. J Clin Endocrinol Metab. 85:569-573.

28. Wit JM, Kamp GA, Rikken B. 1996 Spontaneous growth and response togrowth hormone treatment in children with growth hormone deficiency and idiopathic short stature. Pediatr Res. 39:295-302.

29. Burns EC, Tanner JM, Preece MA, Cameron N. 1981 Final height and pubertal development in 55 children with idiopathic growth hormone deficiency, treated for between 2 and 15 years with human growth hormone. Eur J Pediatr. 137:155-164.

30. Palmert MR, Mansfield MJ, Crowley Jr WF, Crigler Jr JF, Crawford JD, Boepple PA. 1999 Is obesity an outcome of gonadotropin-releasing hormone agonist administration? Analysis of growth and body composition in 110 patients with central precocious puberty. J Clin Endocrinol Metab. 84:4480-4488.

31. Rogol AD. 1998 Editorial: leptin and puberty. J Clin Endocrinol Metab. 83:1089-1090

32. Walvoord EC, Pescovitz OH. 1999 Combined use of growth hormone and gonadotropin-releasing hormone analogues in precocious puberty: theoretic and practical considerations. Pediatrics. 104:1010-1014. 